\title{
Cognitive Styles: Characterization of College Students' Creative Mathematical Thinking
}

\author{
Sri Rahayuningsih ${ }^{1 *}$, Toto Nusantara ${ }^{2}$, Abdurrahman As'ari ${ }^{2}$, Hery Susanto ${ }^{2}$ \\ ${ }^{1}$ Postgraduate Program in Mathematics Education, State University of Malang, Mathematics Department, \\ STKIP YPUP Makassar \\ ${ }^{2}$ Mathematics Department, Faculty of Mathematics and Natural Science, State University of Malang
}

*Corresponding Author: Sri Rahayuningsih, Postgraduate Program in Mathematics Education, State University of Malang, Mathematics Department, STKIP YPUP Makassar

\begin{abstract}
:
Purpose: This study aimed to discuss college students' creative mathematical thinking in open-ended problem solving. In particular, this study would attempt to characterize the differences in students' creative mathematical thinking skills based on cognitive styles.

Research Method: This study employed a descriptive qualitative design. The population of this study consisted of 105 pre-service elementary school teachers who were enrolled in the fifth semester classes at Universitas Muhammadiyah Makassar. Open-ended problem solving sheets and interview guidelines were developed as the instruments to measure the students' creative mathematical thinking. Meanwhile, to group students based on their cognitive styles, Group Embedded Figure Test (GEFT) was conducted. The students were categorized into field independent (FI) and field dependent (FD) students.
\end{abstract}

Findings: In general, the results reported that both the FI and FD students could perform all the aspects of creative mathematical thinking (flexibility and fluency) in solving open-ended problems. However, unlike the FD students, the FI students were able to generate more various and unique ideas (more flexible) because they possessed higher spatial reasoning skills. On the other hand, despite mistakes in calculation, the FD students always did an evaluation quickly and fix the answers as soon as possible (fluency).

Implications for Research and Practice: The implications of the current study were addressed to educational practices, especially at the tertiary level. In addition, the results of this study also provide an insight for the development of mathematical creative thinking assessment or evaluation tools.

Keywords: Problem Solving, Open-Ended, Creative Mathematical Thinking, Cognitive Style

\section{INTRODUCTION}

Rapid changes and complexity found in all aspects of life characterize the contemporary society. People living in this community cannot be separated from creativity because creativity serves as the key factor to dealing with challenges caused by the changes. Creativity also functions as the main drive to generate advanced knowledge. These statements have made creativity a hot issue to discuss among experts and practitioners in education.

To successfully achieve the contemporary society goals, Indonesian policy makers should be fully concerned with the development of university students' creativity. A preliminary study conducted to pre-service mathematics teachers studying at four universities in Makassar, Indonesia has revealed that it is necessary for college students to improve their creativity in solving mathematical problems (Rahayuningsi, 2017). Rahayuningsih (2017) found that 90,47\% of the students could not understand creative thinking concept and $99,04 \%$ of the students were not well informed about how to measure students' creative thinking skills. These findings indicated that the university students or the preservice mathematics teachers were still unable to understand, recognize, and use creative thinking skills in learning.

Siswono (2015) points out that creativity results from thinking process that generates a new and original perspective on a particular problem or situation. This definition suggests that creativity is 
actually the product of creative thinking. Creative thinking and creativity have one similar trait. Both of them are defined as the ability to focus on quantity, usability, and diversity in interpreting available data or information to discover many possible solutions to a problem. Therefore, it can be said that in cognitive domain, creative thinking and creativity have the same definition. To emphasize this, the next section will discuss creative thinking as perceived similar to creativity (Munandar, 1999).

The nature of mathematics is frequently associated with ideas, structures, and relationship organized logically. Therefore, mathematics can be used as a tool to evaluate the development of creativity (Sriraman, 2009; Nadjafikhah, 2012; Voica \& Singer, 2013; Singer, 2015, 2016; Akgul \& Kahveci, 2016). A mathematical truth is expanded based on rationales and mathematical operations often include making and testing hypotheses, seeking for an analogy, creating connection, representation and generalization, building a communication, proving a theorem, and solving a problem. Performing these acts require some critical thinking skills; one of which is creative thinking.

Mathematical creativity is something challenging due to its complicated structures and characteristics. It is difficult to define the characteristics of mathematical creativity (Mann, 2005; Sriraman, 2005, Sriraman \& Lee, 2011). Mathematical creativity is often perceived as a professional mathematician (Sriraman, 2005). Radjafikah (2012) points out that in finding a mathematical concept, someone can make connection or combination among existing prior concepts that also constitute creative work in mathematics. Sriraman (2004) states that creativity is not only related to the original work of a professional mathematician, but an individual's ability to solve a problem which he or she has never encountered before can also be considered as a creative act. This opinion is also strengthened by Chamberlin (2005) who asserts that mathematical creativity can be observed when someone successfully produces unique solutions to a problem which cannot be cracked with common methods. Furthermore, NadjaFIkhah (2012) assumes that an unusual problem solving method constitutes the novelty or the originality of one's mathematical creative ability.

Solving an open-ended mathematical problem is one of the appropriate instruments to measure an individual's creativity (Zalenskiy, 2013; Mihajlovic, 2015). An open-ended problem solving can be used as a vehicle to reveal creative thinking and develop one's creative thinking ability which is also related to divergent thinking in solving a problem. Measuring mathematical creativity potentials in schools has been studied previously (Akgul \& Kahveci, 2016). Akgul \& Kahveci (2016) revealed that if mathematical creativity could be measured, the school curriculum could be adjusted to the creative students' needs. Meanwhile, to improve students' creativity, various approaches and assessments have been developed by experts. However, little emphasis is put on the development of students' creativity at the university level. Therefore, this study attempted to discuss mathematical creativity performed by university students or pre-service teachers in solving an open-ended problem. The specific purpose of the current study was to characterize differences in students' mathematical creative thinking at the university level.

Thinking skills play a crucial role in problem solving (Gur, 2018). An individual's ability to find a different problem solving method is one of the characteristics of mathematical creative thinking skills. Zalenskiy (2013) affirms that the use of problem's solutions or approaches can result in students' having knowledge flexibility and ability to solve an unfamiliar problem. Didin (2017) emphasizes that an individual who possesses an interpersonal problem solving skill is more emphatic and more sensitive towards a problem. She or he can perceive something from a different perspective, generate a creative solution, express her/himself, and build a causal relationship. One of the instance of problems that can stimulate one's creativity is an open-ended problem. An open-ended problem provides an opportunity for students to acquire knowledge/experiences in discovering, recognizing, and solving problems with a wide range of techniques and strategies.

To investigate university students' creative thinking ability, it is necessary to look at numerous dimensions of human beings because university students have different individual traits. Basically, every individual is unique. Individual differences may include intelligence, thinking ability, creativity, cognitive styles, attitudes, and interests. One trait that can influence an individual to process information is cognitive style (Overton, 200 8; Angeli, 2013; Philip, 2016). Based on some previous research findings, cognitive styles fall into two major categories, field independent (FI) and field dependent (FD) (Ghani, 2004; Reid, 2014; Chu, 2007; Angeli, 2013; Philip, 2016). The differences in cognitive styles can be measured by a test known as Group Embedded Figure Test (GEFT) (Ghani, 2004; Chu, 2007; Angeli, 2013; Reid, 2014; Philip, 2016). 
Research examining cognitive styles in mathematical creativity has been conducted by Singer et al (2016). Singer concluded that the nine cognitive style problem posing (PP) found were effective to measure university students' mathematical creativity in geometry. The results of the research conducted by Singer et al. involved assessment on FI subjects only. No recent study has reported findings on FI and FD students' creativity in mathematics. Therefore, this study aimed to explore the creative ability of university students whose cognitive styles included FI and FD in solving an openended problem.

The present study would attempt to describe the creative thinking ability of the FI and FD pre-service elementary teachers or university students who were enrolled in fifth semester classes of Elementary Education, Universitas Muhammadiyah Makassar. The students' creative thinking ability in an openended problem solving would be observed from two aspects, flexibility and fluency. Flexibility includes the ability of the students to elaborate various solutions and provide more than one possible answers. Fluency takes into account the ability of the students to interpret answer fluently and appropriately and even if there is an error occurring in the process, the students can quickly recover the answer. The research problem, thus, can be formulated as "What are the characteristics of the field independent (FI) and field dependent (FD) university students' creative thinking skills?"

\section{METHOD}

\subsection{Research Design}

This study was designed as a qualitative descriptive study (Overton, 2015; Kuzle, 2016), of which aim was to explore the creative thinking ability of the FI and FD pre-service elementary teachers or university students who were enrolled in fifth semester classes of Elementary Education, Universitas Muhammadiyah Makassar in solving an open-ended problem. Qualitative research is a study focused on understanding a phenomenon experienced by the subjects: behaviors, perceptions, motivation, and actions (Punch, 2005; Cer, 2018). Data was collected though observation, documentation, and think aloud sessions which allowed researchers to analyze real perceptions and phenomena (Ericson \& Simon 1993; Overton, 2015; Cer, 2018).

\subsection{Research Sample}

The population of the study involved 105 pre-service elementary teachers who were registered in fifth semester classes at Elementary Education department of Universitas Muhammadiyah Makassar. The students aged between 18-20 years old. The results of the GEFT test showed that 14, $28 \%$ of the students can be categorized as Field Independent (FI), 19,04\% were Intermediate and 66,67\% were field dependent (FD). The samples of this research would include the FI and FD students only.

\subsection{Research Instrument and Procedures}

The main instrument of this study was the researcher. Other complementary instruments consisted of GEFT (Group Embedded Figure Test) developed by Wikin et al.,1977,1981 (Reid, 2014) and an open-ended problem solving test. GEFT was conducted to determine the participants' cognitive styles. The test contained 25 items in the form of images. GEFT test was performed within 3 sessions. In the first session, the students were required to work on 7 problems and in the second and third session, the students were required to work on 9 problems. The total possible score that the students might achieve from session 2 and 3 was 18; every correct answer was worth 1 point. Students whose score ranged between 0-6 were categorized into field dependent, 7-12 were categorized into intermediate, and 1318 were categorized into field independent. The open-ended problem solving test was done to investigate the students' creative thinking ability. Each group of students (FI and FD) did the test separately. The results of the test indicated that there were only three students from the FI group and two students from the FD group able to solve the open-ended problems. Two students from each group were selected as representatives. Students who could perform flexibility and fluency in solving the problems were considered to be competent in thinking creatively. The open-ended problem presented to the participants was described as follows:

- Draw as many geometric 3D shapes as possible and determine every edge of the shape until the volume turns $343 \mathrm{~cm}^{3}$.

- Show and Explain your answer in details! 
The procedure of collecting the research data employed a task-based interview in which the subject was given a piece of paper and a pencil to solve an open-ended problem and required to tell his/her thinking process in details (Ovlas, 2016). This process is called think aloud method. Clinical interviews and observation were conducted afterwards to trace why the student made such decisions and other possible solutions. The results of the interviews were documented using a camcorder (Ovlas, 2016).

\subsection{Data Analysis}

Data analysis had started since the researcher worked on the field. While data was collected, an analysis was performed on questions asked based on the responses of the subjects. For instance, if a subject's response was not appropriate with the aim of the research and if the researcher thought the response was not appealing, the researcher was responsible to make the question more understandable so that more comprehensive answers from the subject could be elicited. However, if the response was interesting enough to reveal, the researcher might ask a different question that could dig deeper his/her answer. Recording data was transcribed. Data transcription, the results of the open-ended test, and physical behaviors of the subjects were analyzed in four steps: data analysis, data reduction, data display, and conclusion drawing (Creswell, 2014).

\section{FINDINGS}

The participants' mathematical creative thinking ability was described as follows. The FI students were able to understand the problem since the beginning. It can be seen from the way the students elaborated what had been known and what had been asked. Meanwhile, the FD students took longer to figure things out though eventually they were able to understand the problem well. The FI students perceived problems by making a plan. Therefore, possible errors that might occur during the process could be predicted. In contrast, the FD subjects were more likely to rush things and were in hurry in calculating numbers. Followings are the excerpts of the think aloud interviews conducted to the FI and FD students related to the early stages of problem solving.

$P$ (Researcher) : Do you understand the problem?

FI (Field Independent Student) : (read it many times) I understand.

$P$ : What can you understand from the problem?(pointing at the paper)

FI: I was asked to draw different geometric 3D shapes with the same volume that is $343 \mathrm{~cm} 3$.

$P$ : How do you solve the problem? Why can you solve it that way?

FI: (a few minutes later) First, I elaborated what had been known and what had been asked. After that, I thought about some familiar geometric 3D shapes. The only known aspect was the volume (343 cm3) which makes this problem more challenging to me.

The interview excerpts suggested that the FI student was able to understand the problem and attempt to find a strategy to solve it. The student also tried to outline known aspects of the problem even though he realized that the information given related to that was very limited and he noticed that it became more challenging to solve the problem. At the early stage of the problem solving process, the FI student had already formed an imagination that allowed him able to explain his thoughts and think about familiar geometric 3D shapes. He was able to relate the problem with the concept that he had learned before. A similar interview was also conducted to an FD student. Followings are the excerpts:

$P$ (Researcher) : Do you understand the problem?

FD (Field Dependent Student) : (looked confused while scratching his head) May I read the problem once more?

P: Of Course

FD: (a few moments later) I have understood the problem, Mam.

$P$ : Can you prove it?

FD: (while crossing out the answers and explaining) I have to draw some $3 D$ geometric shapes with the same volume $343 \mathrm{~cm} 3$

P: How do you solve the problem? Why can you solve it that way?

FD: (still looked confused and a few minutes later) I think I can draw two 3D shapes, a cube and a cuboid. 
Based on the interview excerpts, it can be concluded that the FD student could understand the problem though it took quite a long time for him to elaborate the known aspects. The interview also proved that the FD student had started planning on seeking a strategy to solve the problem that was to draw a cube and a cuboid with the same volume $(343 \mathrm{~cm} 3)$.

At the early stage of the problem solving process, the FI and FD students were reported able to comprehend the problem. However, when they encountered the next stage where they needed to solve the problem, various answers were offered. The FI student was able to find seven alternatives while the FD student was only able to provide two distinguished ideas. The discrepancy between the FI and FD students' answers was also reflected in the way they did an algebraic calculation. Followings are the differences found between them.

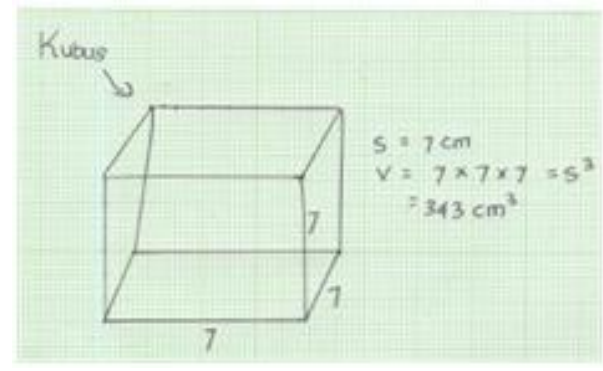

Figure1. FI Student's Answer

Figure 1 clearly shows that an FI student was able to comprehend the problem very well. The student elaborated what had been known and what was being asked. The FI student first wrote $S=7$; $S$ referred to the length of the edge of the cube in centimeters $(\mathrm{cm})$. After that, he wrote $\mathrm{V}=7$. 7.7 , where $\mathrm{V}$ referred to the volume of the cube which could be broken up into 7.7.7 (multiplication) and resulted in $343 \mathrm{~cm} 3$.

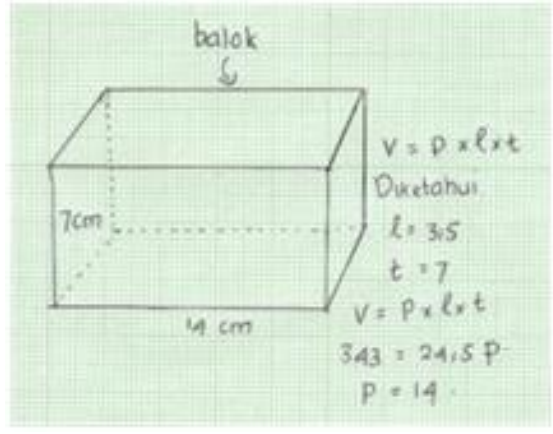

Figure1.2. FI Student's Answer

Figure 1.2 presents the second answer from the FI student. Obviously, the FI student was able to find alternatives to the answer with different processes. The student found another geometric 3D shape with the same volume $(343 \mathrm{~cm} 3)$, a cuboid of which width was $3,5 \mathrm{~cm}$, height was $7 \mathrm{~cm}$, and length was $14 \mathrm{~cm}$. This process of finding another new corresponding new shape indicated that the student performed flexibility in thinking.

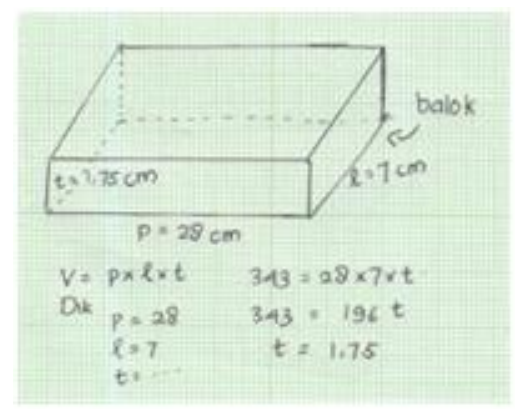

Figure1.3. FI Student's Answer

Figure 3.1 shows the third answer from an FI student. A different cuboid with different width $(7 \mathrm{~cm})$, height $(1,75 \mathrm{~cm})$, and length $(28 \mathrm{~cm})$ was found (compared to figure 1.2$)$. 


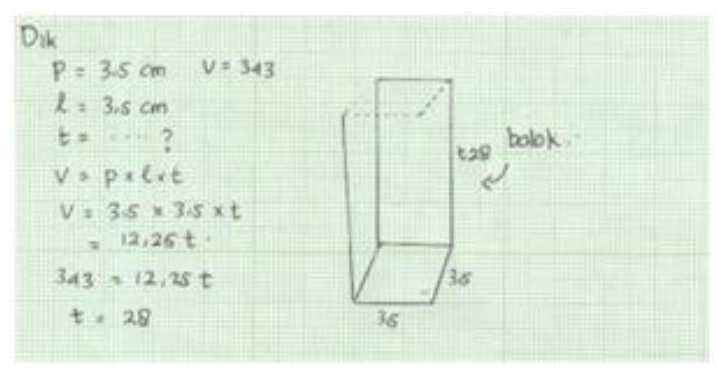

Figure1.4. FI Student's Answer

Another possible answer proposed by the FI student was presented by Figure 1.4. The student was able to draw another cuboid with different length and width $(3,5 \mathrm{~cm})$ and height $(28 \mathrm{~cm})$.

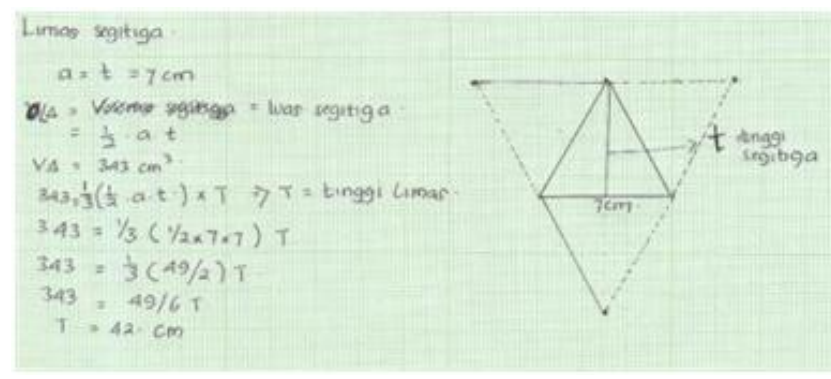

Figure1.5. FI Student's Answer

Figure 1.5 shows the FI student's attempt to find the triangular area of a triangular-faced pyramid. To figure out the volume of the shape, the student wrote $\Delta=$ the triangular area of the base, a = the length of the edge of the base (in $\left.\mathrm{cm}^{2}\right), \mathrm{t}=$ the height of the edge of the triangle, $\mathrm{T}=$ the height of the pyramid, and $\mathrm{V}=$ the volume of the pyramid. The elaboration resulted in $\mathrm{a}=\mathrm{t}=7 \mathrm{~cm}$ so that $\mathrm{T}=42$ $\mathrm{cm}^{2}$



Figure1.6. FI Student's Answer

Figure 1.6 presents the attempt of the FI student to find the height of a square-based pyramid of which volume was $343 \mathrm{~cm}^{3}$. The student wrote $\mathrm{s}=7$ (the length of the edge of the base or the square), thus found $\mathrm{t}=21 \mathrm{~cm}$ (the height of the pyramid was $21 \mathrm{~cm}$ ).



Figure1.7. FI Student's Answer

Figure 1.7 shows the ability of the FI to discover a combination of a cuboid and a square-based pyramid. The student made an adjustment, such as shown by Figure 1.7 where $\mathrm{s}=7 \mathrm{~cm}$ (the length of the edge of the pyramid and the edge of the cuboid in $\mathrm{cm}$ ), thus $\mathrm{t}=9 \mathrm{~cm}$ (the height of the pyramid in 
$\mathrm{cm}$ ), and $\mathrm{t}=4 \mathrm{~cm}$ (the height of the cuboid in $\mathrm{cm}$ ). From the explanation, it can be seen that the FI student was able to find 7 alternatives and undergo 7 processes to solve the problem. On the other hand, the FD student's answers could be explained as follows.

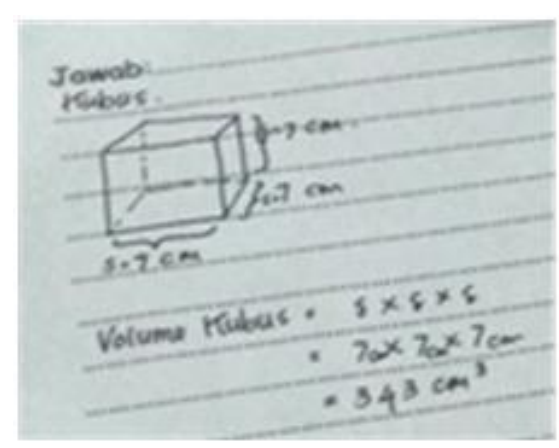

Figure2. FD Student's Answer

The FD student's answer was presented by Figure 2. The student wrote a cube as the answer. He found that if the volume was $343 \mathrm{~cm}^{3}$, then the possible length of the edge of the cube was $7 \mathrm{~cm}$.

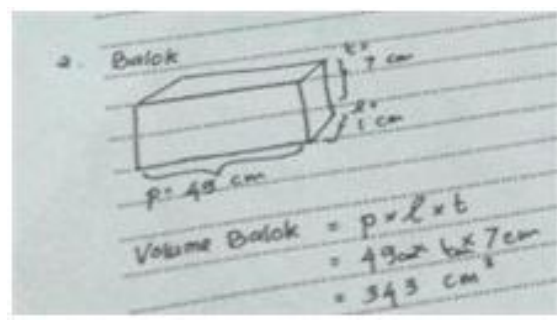

Figure 2.1 FD Student's Answer

Figure 2.1 shows that the FD student could find another alternative to the question in a different way. He figured out that if the volume of a cuboid was $343 \mathrm{~cm}^{3}$ then the possible length of the shape was 49 $\mathrm{cm}$, the width was $1 \mathrm{~cm}$, and the height was $7 \mathrm{~cm}$. With the same way, the FD student discovered another geometric shape which he thought was different from the earlier (figure 2.2).



Figure2.2. FD Student's Answer

The cuboid presented by figure 2.2 was in fact similar to the previous (Figure 2.1). If it is observed closely, we could find that the combination of elements of cuboid in Figure 2.1 and Figure 2.2 were exactly the same $(1,7,49)$. The difference lied on the position of the two shapes. From the explanation of both the FI and FD student's answers, it can be concluded that the FI student could figure out seven alternatives, three different cuboids and one combination of a cuboid and a square-based pyramid. In contrast, the FD subject was only able to find two types of 3D shapes, two similar cuboids and one cube. These findings were confirmed by the results of the think-aloud interviews such as shown below.

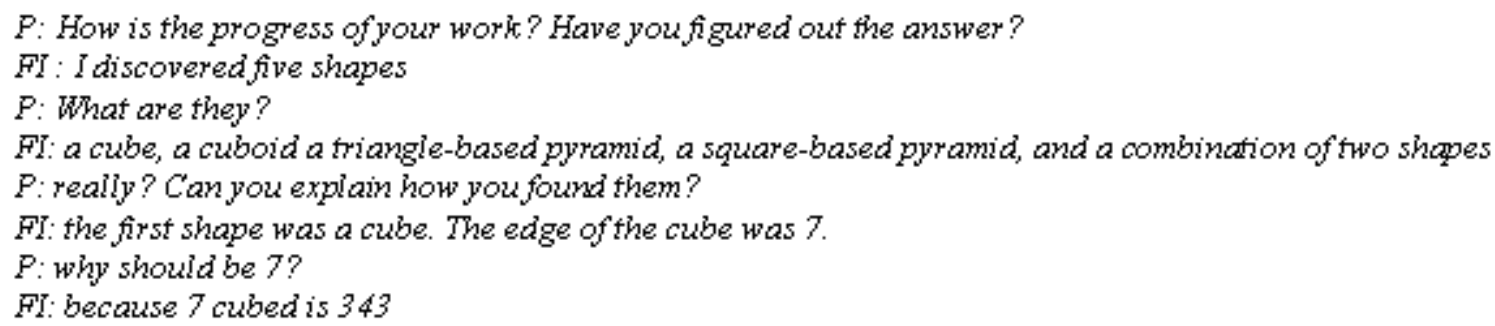




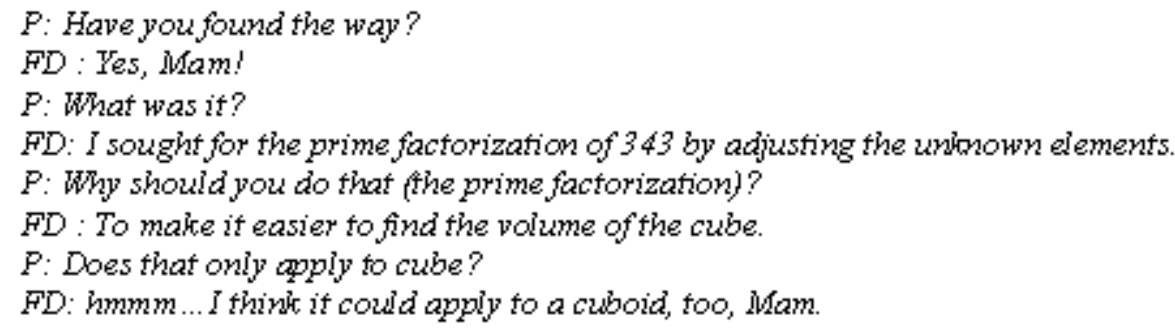

The excerpts of the interviews indicated that the FI student could perform better flexibility in thinking compared to the FD subject. The FI student was obviously able to report many different answers to the question, able to determine each edge of the shape correctly, able to adjust the prime factorization of 343, and able to avoid producing irrational numbers that had potential to complicate the process. Both FI and FD students were making an adjustment by finding the prime factorization of 343, but the FI student could extend the concept by using fractional numbers 3,5 and avoiding irrational numbers. As a result, the FI student found it easier to operate the numbers and draw the shape. Followings are the excerpt of an interview conducted to the FI student related to the process.

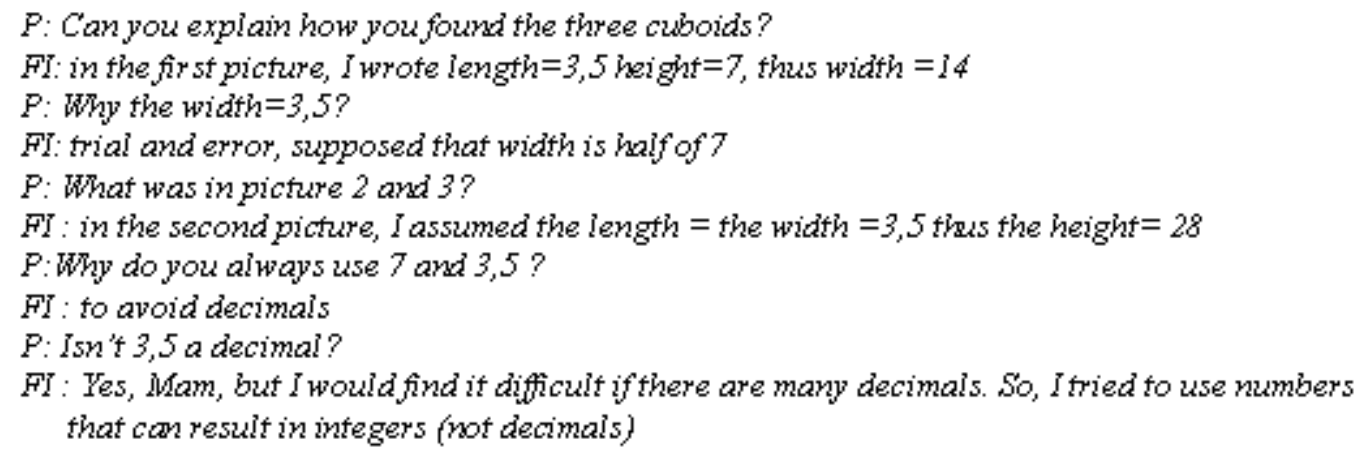

Fluency includes the ability of students to interpret answers fluently and appropriately and even if there is an error occurring in the process, the students can quickly recover the answer. Both FI and FD students have fulfilled the indicators of fluency, but the FD student had a more frequent tendency to encounter an error in operating numbers and took longer to solve a problem. Even so, the FD student was always able to correct and recheck the answer before it was finally submitted.

Figure 1.7 shows a geometric shape formed by the FI student from the combination of a cuboid and a square-based pyramid. The excerpts of the interview conducted to an FI subject indicated that the student had the ability to find unique answers which could not be found in FD students. Even though FD students could discover more than one answers, the FI students could present more varieties to it. The ability of FI students to bring up various alternatives reflects their thinking flexibility and fluency.

If it is meticulously observed, there is no significant difference found in between FI and FD students' mathematical creative thinking ability. FI students could present more varied answers while FD students could not. However, the two groups were able to interpret the answers appropriately and despite errors made by the FD students, they still tried to fix them. These findings, therefore, suggested that FI and FD students had met the two major criteria of creative thinking, flexibility and fluency, in solving an open-ended problem.

\section{Discussion AND CONCLUSIONS}

The results of the current research indicated that both FI and FD students performed a mental activity through some steps: problem orientation, problem identification or formulation, problem comprehension, and problem solving (is the information adequate?), ideas construction by synthesizing ideas found in the text. The students were reported able to interpret the relationship between the concepts based on the information given. They were also able to make a decision that the information was not sufficient to solve the problem. In line with the finding, Sriraman (2004) underlines some preparation steps that a scientist will go through before solving a problem. These stages include: (1) reading literature; (2) communicate the problem with other mathematician; (3) try to act heuristically; (4) apply the working backwards approach, and guess, and (5) looking for the linkages between the problem and natural phenomenon. Findings by Sriraman (2004) implicitly 
suggest that every scientist will undergo such steps if they encounter a dead end after putting a lot of effort on solving the problem or in other words after encountering numerous failures.

Findings also showed that the FI students tended to be more fluent in confirming their interpretation of the answers. They almost made no mistakes in calculation. It suggested that the FI students had met the indicator of fluency in solving an open-ended problem. This finding was in line with those by Guisande \& Adelina (2012) who concluded that field independent (FI) children could achieve better scores in solving problems involving pictures compared to field dependent (FD) students. The FI students seemed to be always confident with their opinions and more open to critics (Angeli, 2013); thus, their performance could surpass that of the FD students.

Based on the results of the GEFT test, it can be concluded that the FI students performed better in open-ended problem solving. This finding was corroborated with that of Overton, et al., (2008) who found a correlation between one's cognitive style (field independent) and his/her ability to solve problems. The errors made by the FD students during the problem solving process might result from their lack of focus on the problem. The FD students found difficulties in finding information because they were hindered by another contextual stimulation (Minchekar, 2017).

The FD students had an ability to process information properly and recognize the framework or the pattern of the task. Singer (2016) states that students who have mathematical creative thinking ability are those who are able to change their mental frame (framework) or to identify problems using a new and unusual method (i.e., change in cognitive framing). Similarly, Trigo (2016) points out that an individual's thinking fluency in mathematics can be observed from his or her ability to recognize the framework or the pattern of the task.

In general, students' mathematical creative thinking ability differs across cognitive styles. Despite the differences, there are also some similarities found between them. It had been shown that both FD and FI students had met the characteristics of creative thinking, flexibility and fluency. However, the FI students were able to produce more varied answers to the problem and had been proven more fluent in interpreting their answers and describing their thinking processes compared to the FD students. In contrast, the FD students were only able to find two answers to the problem. The FD students could not avoid making calculation mistakes, but once they encountered an error they always tried to recheck their answer before it was submitted.

The results of data analysis suggested that both FI and FD students had met the characteristics of mathematical creative thinking, flexibility and fluency, in solving an open-ended problem. In regards with fluency, the FD students made calculation mistakes more frequently compared to the FI students, but the FD students always evaluated their answer before it was submitted. In contrast, the FI students were more likely to produce correct answers and more able to describe their answers fluently because the students were reported to have higher spatial reasoning ability which allowed them to seek for more varied and unique solutions to the problem. Akgul \& Kahveci (2016) recorded that spatial ability played a significant role in developing creativity. Despite the difference in their spatial ability, both FI and FD students had fulfilled all the aspects of mathematical creative thinking ability. Therefore, each of them could generate unique ideas and solutions to the problem (flexibility).

\section{RECOMMENDATIONS}

It is strongly recommended for other researchers to explore more about an assessment tool that can be used to measure students' mathematical creative thinking process in solving an open-ended problem by still considering the students' cognitive styles (FI and FD). Even though research findings suggested that both FI and FD students were able to perform creative thinking ability in mathematics, each of them applied a unique approach to solving the problem. The FD students had a tendency to make mistakes in calculations, but at the same time they were still concerned with the result so that they tried to evaluate their answer before it was submitted. On the other hand, the FI students had high spatial reasoning which allowed them to discover more varied and distinctive alternatives to the problem.

The implications of the current study were addressed to educational practices, especially at the tertiary level. The university students' success in solving mathematical problems depends on the students' creativity. Therefore, if the students are able to recognize their cognitive styles, they would be able to solve different problems with different methods. Given this information, lecturers thus have a 
responsibility to provide guidance for the students to use their skills optimally. In addition, the results of this study also provide an insight for the development of mathematical creative thinking assessment or evaluation tools.

\section{REFERENCES}

[1] Akgul. S., \& Kahveci, N. G. (2016). A study on the development of a mathematics creativity scale. Eurasian Journal of Educational Research, 62, 57- 76.

[2] Cer, E. A. (2018). Comparison of Mother-Tongue Curricula of Successful Countries in PISA and Turkey by Higher- Order Thinking Processes. Eurasian Journal of Education Research, 73, 95-112.

[3] Chu, Y. C., \& Reid, N. (2012). Genetics at school level: addressing the difFIculties, Research in Science and Technological Education, 31(1), 1-25.

[4] Creswell, J. W. (2014). Research Design: Qualitative, Quantitative and Mixed Methods Approaches (4th ed.). Thousand Oaks, CA: Sage.

[5] Didin, E., \& Akyol, A. K. (2017). The Relationship of Art and Music Education with Adolescents' Humor Styles and Interpersonal Problem Solving Skills. Eurasian Journal of Education Research, 72, 43-62.

[6] Ericsson K. A. \& Simon H. A. (1993). Protocol Analysis: Verbal Reports as Data, Cambridge, MA: MIT Press.

[7] Ghani, S. A. (2004). Attitudes, Performance, and Psychological Characteristics of Student Teachers Learning Introductory Statistics. PhD Thesis, Glasgow: University of Glasgow.

[8] Gur, C., \& Kocak, N. (2018). The effect of TMPT program on pre-school children's social problem solving skills. Eurasian Journal of Education Research, 73, (77-94).

[9] Liljedahl, P., Trigo, M.S., Malaspina, U., \& Bruder, R. (2016). Problem Solving in Mathematics Education. Icme-13 Topical Surveys. Hamburg, Germany.

[10] Mann, E. L. (2006). Creativity: The essence of mathematics. Journal for the Education of the Gifted, 30(2), 236-260.

[11] Mihajlovic, A. (2015). Using open-ended problems and problem Posing activities in elementary Mathematics. The 9th International MCG Conference, 34-39, Sinaia, Romania.

[12] Minchekar, V. S. (2017). The Role of Cognitive Style in Creative Thinking among College Students. Psychology and Behavioral Science International Journal, 6 (1), 1-3.

[13] Munandar, U. (1999). Pengembangan Kreativitas Anak Berbakat. Jakarta: Pusat Perbukuan Depdikbud dan Rineka Cipta.

[14] Nadjafikhah, M., \& Yaftian, N. (2012). The frontage of Creativity and Mathematical Creativity. International Conference on University Learning and Teaching, Procedia Social and Behavioral Sciences 90 ( 2013 ), 344-350.

[15] Overton, T. \& Potter, N. (2008). Solving open-ended problems, and the influence of cognitive factors on student success. Proceedings Chemistry Education Research And Practice, Manchester.

[16] Ovlas, G. Bulut, N. \& Akcakin, V. (2016). Pre-Service Classroom Teachers' Proof Schemes in Geometry: A Case Study of Three Pree-service Teachers. Eurasian Journal of Education Research, 63, 133-152.

[17] Philip, M. C., \& Ezeh, V. C. (2016). Effect of Field-dependent versus Field-independent cognitive styles on prospective and retrospective memory slips. South African Journal of Psychology, 46 (4), 542-552.

[18] Plucker, J. A., Beghetto, R. A., \& Dow, G. T. (2004). Why isn't creativity more important to educational psychologists? Potentials, pitfalls, and future directions in creativity research. Educational Psychologist, 39 (2), 83-96.

[19] Rahayuningsih, S. (2017). Persepsi Keterampilan Berpikir Kreatif Calon Guru Matematika di Universitas Muhammadiyah Makassar dalam memecahkan masalah Matematika Geometri. Jurnal Matematika dan Pembelajaran, 5 (1), 22-31.

[20] Reid, N. (2014). Field Dependency and Performance in Mathematics. European Journal Of Educational Research, 3 (1), 43-57.

[21] Singer, F. M. (2015). Is problem posing a tool for identifying and developing Mathematical creativity. Singer, N. Ellerton, \& J. Cai (Eds.), Mathematical problem posing: From research to effective practice. NY: Springer.

[22] Singer, F. M., Voica, C., \& Elczer, I. (2016). Cognitive styles in posing geometry problems: implications for assessment of mathematical creativity. ZDM Mathematics Education, 49, 37-52.

[23] Siswono, T., \& Rosyidi, A. (2005). Menilai Kreativitas Siswa dalam Matematika. Seminar Nasional Matematika dan Pendidikan Matematika, Jurusan Matematika FMIPA UNESA. Surabaya.

[24] Sriraman, B. (2009). The Characteristics of Mathematical Creativity. ZDM Mathematics Education, 41, 19-27. 
[25] Sriraman, B., \& Lee, K. K. (Eds.). (2011). The Elements of Creativity and Giftedness in Mathematics, What are the Elements of Giftedness and Creativity in Mathematics?, 1-4, TheUniversity of Montana, USA.

[26] Voica, C., \& Singer, F. M. (2013). Problem modification as a tool for detecting cognitive flexibility in school children. ZDM: the international journal on mathematics education, 45 (2), 267-279.

[27] Winkler. (2007). Creativity In Higher Education report on the Eua Creativity Project 2006-2007. the European University Association.

[28] Witkin, H. A., Dyk, R. B. Faterson, H. F, Goodenough, D. R. \& Karp, S. A. (1974). Psychological Differentiation: Studies of Development. New York: Lawrence Erlbaum Associates Inc.

[29] Zalenskiy, A. Z. (2013). Multiple Solutions of A Problem: Find the Best Point of the Shot. Australian Senior Mathematics Journal, 27 (1), 47-55.

\section{AUTHORS' BIOGRAPHY}

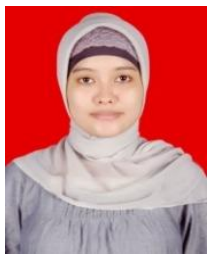

Sri Rahayuningsih, is currently teaching at the Mathematics Education Study Program . Faculty of Teacher Training and Education STKIP YPUP Makassar, Indonesia. The Scientefic field of Mathematics Education The resesearch area, wich is currently involved in the development of scientific content in mathematics education, is being integrated into educational products such as research based teaching materials and book reference based on research for pre services mathematics teacher

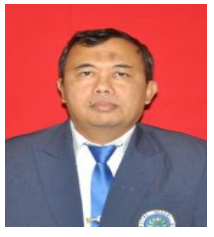

Toto Nusantara, is a lecture at the Faculty of Mathematics an Natural Sciences, Universitas Negeri Malang, Indonesia. Field of science Mathematics, Has Published several articels in international journals in the field of mathematics and issues of mathematics education in learning.

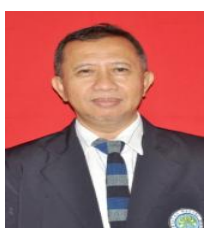

Abdurrahman As'ari, is a lecture at the Faculty of Mathematics an Natural Sciences, Universitas Negeri Malang, Indonesia. Field of science MathematicsEducation, Has Published several articels in international journals in the field of mathematics and issues of mathematics education in learning.

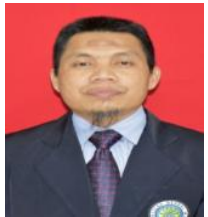

Hery Susanto, is a lecture at the Faculty of Mathematics an Natural Sciences, Universitas Negeri Malang, Indonesia. Field of science Mathematics, Has Published several articels in international journals in the field of mathematics and issues of mathematics education in learning.

Citation: Sri Rahayuningsih, et.al.. "Cognitive Styles: Characterization of College Students' Creative Mathematical Thinking ". International Journal of Humanities Social Sciences and Education (IJHSSE), vol 6, no. 3, 2019, pp. 50-60. doi: http://dx.doi.org/10.20431/2349-0381.0603007.

Copyright: () 2019 Authors. This is an open-access article distributed under the terms of the Creative Commons Attribution License, which permits unrestricted use, distribution, and reproduction in any medium, provided the original author and source are credited. 